\title{
INFLUENCE OF WHEEL AXLE STIFFNESS CHARACTER TO THE WHEEL/RAIL DYNAMIC CONTACT ON THE STRAIGHT TRACK
}

\author{
Weihua $\mathrm{Ma}^{1}$, Zhiqiang $\mathrm{Xu}^{2}$, Shihui $\mathrm{Luo}^{3}$, Rongrong Song ${ }^{4}$ \\ 1,2,3 Traction Power State Key Laboratory, Southwest Jiaotong University, Chengdu, China \\ ${ }^{4}$ College of Computer Science and Technology, Southwest University for Nationalities, Chengdu, China
}

Submitted 4 August 2012; accepted 12 December 2012;

first published online 16 October 2013

\begin{abstract}
The influence of the wheel axle bending stiffness to the wheel/rail contact dynamic force and wheelset vertical vibration of the linear metro vehicle on a straight track was investigated. Based on a vehicle dynamic model and two kinds of elastic wheelset models, a comparison was carried out between the wheelset vertical vibration and the wheel/rail vertical force. Simulation results showed that the wheelset vibration and the wheel/rail vertical force of the elastic wheelset model were different with that of the rigid wheelset model; this was due to the BM3000 type wheelset not having high enough bending stiffness. In contrast, the result of the elastic wheelset model of the wheelset of the Beijing metro railway vehicle was quite similar to the results of the rigid model since a larger bending stiffness was used. Consequently, the wheelset vibration and wheel/rail vertical force can be decreased by increasing the wheel axle bending stiffness which will improve wheel/rail dynamic contact conditions.
\end{abstract}

Keywords: metro vehicle; elastic wheelset model; wheel axle bending stiffness; wheelset vertical acceleration; wheel/ rail contact force.

\section{Introduction}

With the improvement of running speed and the increase of axle load, much wear and damage occurs on the wheel axle of railway vehicles (Zhao et al. 2010). Numerous numerical simulations and practical experiments have been carried out to study the wheel axle damage problem and significant achievements have been obtained (Zerbst et al. 2005). However, these research studies mainly focus on the improvement of the intensity and reliability of the wheel axle while ignoring the effects of the wheel axle stiffness characteristics which have a considerably important influence on the wheel/rail dynamic contact force (Madia et al. 2008; Iwnicki 2009), and it also has a significant effect on track dynamic deflection (Knothe, Grassie 1993; Chaar, Berg 2006) and ground vibration problem (Kouroussis et al. 2010).

Aimed at the severe wear problems that have occurred in one of the metro vehicle lines in China which adopted the BM3000 type wheelset, the department concerned carried out a large amount of investigations, such as the optimization of the wheel/rail profile and wheel/rail contact geometry, material quality improvement and even the optimization of the positioning parameters of the journal box. Although the wheel tread wear problem was improved to some extent through the above mentioned methods, the source which caused the serious wear was still not found so the problem was not completely solved (Li et al. 2010; Xu et al. 2010). Generally speaking, the influence of the bending stiffness character of the wheel axle is not taken into consideration in wheel/rail contact dynamics and the wheelset was set up as one rigid body in common railway vehicle dynamic simulations (Auciello et al. 2009; Wickens 2003; Iwnicki 2003). The wheel axle stiffness was considered as very big and could not reflect the real deflection of the wheel axle at present numerical simulation. In fact, the stiffness characteristic of the wheel axle has a large effect on the wheel/rail dynamic force, especially during high speed and heavy axle load operating conditions.

With developments in computer technology and dynamic simulation methodologies, more and more

Corresponding author: Weihua Ma

E-mail: maweihua2008@gmail.com 
wheelset elasticity factors are considered in railway vehicle dynamic simulations. Arnold et al. (2004) compared the running performance of a passenger vehicle on a straight track with a rigid and elastic wheelset model and analysed the running performance close to the critical speed of the two models (Arnold 2004). Kaiser and Popp (2006) analysed the influence of the wheel structure elastic on the running performance and result showed that the critical speed decreased when the elastic wheelset and elastic rail model were adopted (Kaiser, Popp 2006). Combined with the RC7 locomotive dynamic model, Chaar and Berg (2005) studied the influence of the elastic wheelset on the wheel/rail forces, compared the dynamic simulation results with the test results, and pointed out that the wheelset elasticity had a large effect on the wheel/rail contact forces (Chaar, Berg 2005). Based on the rigid wheelset model and the wheelset model which considered the wheel rotation character, Baeza et al. (2008) studied the impact effects of the wheel scale and rail damage to the railway vehicle through a structure vibration method (Baeza et al. 2008). The influence of the wheel elasticity to the wheel polygonization was investigated, too (Meywerk 1999). Jin et al. (2002) concluded that the wheel/rail contact stiffness will decrease if the elastic wheelset and rail were adopted, and point out that under the condition when the creep force was not saturated then the wheel/rail creep force will undergo an obvious decrease (Jin et al. 2002). It was found that the simulation result of the elastic wheelset model was more accuracy than the result of the rigid wheelset model in wheel axle vibration character analyses (Zhang 2009). Chaar and Berg (2006) researched the vehicle and track coupling vibration problem through the model which considered the wheelset elasticity, and then compared the simulation results of the wheel/rail force with real measured results (Chaar, Berg 2006). Many other studies have been carried out regarding the wheel axle torching stiffness character and analyses of its influence to the wheel/rail contact force and wheelset stick-slip vibration (Ma et al. 2011, 2006; Wang et al. 1996, etc.).

Research about these elastic wheelset and wheel axle torch stiffness issues have solved a lot of wheel/rail contact problem, however, research of the wheel axle bending stiffness characteristic have seldom considered the wheel axle stiffness and wheel/rail damage problem together. By taking into consideration the wheel axle elasticity, the wheel axle will inevitably have a vertical bending deflection when suffering a vertical load; this deflection will increase the wheel/rail vertical dynamic force when the speed was high which will have an effect on the wheel tread wear problem, and even influence the running safety of the vehicle in some severe condition.

The influence of the wheel axle bending stiffness to the wheel/rail contact force was researched in this paper. The elastic wheelset models were set up first and imported to the linear metro vehicle dynamic model followed by the set-up of the elasticity/rigid coupling dynamic model. The author compared the wheel/rail vertical force and wheelset vertical vibration acceleration by adopting different wheelset models. The influence of the wheel axle bending stiffness to the wheel/rail dynamic force was also analysed.

In Section 1, the wheel/rail contact geometry relation of the rigid wheelset and elastic wheelset were first described; Section 2 presents the dynamic model of the metro vehicle which adopted a linear induction motor; Section 3 gives the simulation results, such as the wheelset vertical acceleration, wheel/rail contact force and the influence of the wheel axle stiffness on the wheelset vertical acceleration and wheel/rail contact force.

\section{Wheel/Rail Contact Geometry Relationship}

For the rigid wheelset, the left and right wheel/rail contact geometry of the same wheelset are inter coupling and mutually related, as shown in Fig. 1a. For the independent rotation wheels, movement of the left and right wheels are not coupled together and act independently, as shown in Fig. 1b, and the wheel/rail contact geometry of the two wheels just have less relation.

As the two wheels of the rigid wheelset are rigidly coupled together, the wheel/rail vertical/lateral contact geometry of the two wheels is intimately related. The longitudinal, lateral and spin creeping aspects are also closely related. In general, a rigid wheelset has 6 degrees of freedom in the wheel/rail dynamic model, which is the translational and rotational degrees of freedom along or about the $x, y$, and $z$ axes. However, only 4 of them are independent degrees of freedom reasoning the case of rigid coupling. While for the independent rotation wheels, the two wheels are completely decoupled due to the independent movement of the two wheels. As a consequence, wheelset hunting movement does not occur and its self-steering ability is lost, too. During the dynamic simulations, the independent rotation wheel should be considered as a combination of two wheels and a wheel axle, so the number of the degrees of freedom of the independent rotation wheels is higher than that of the rigid wheelset.

a)

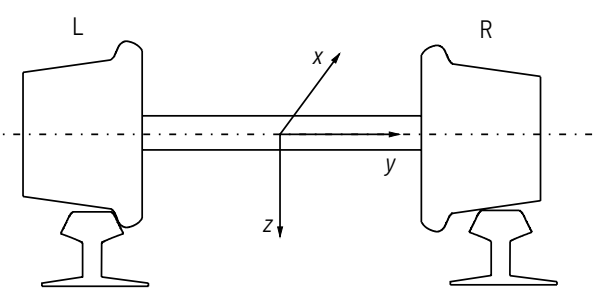

b)

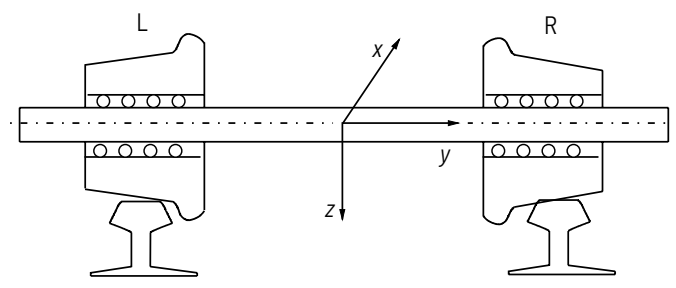

Fig. 1. The schematic diagram of the rigid wheelset and the independent rotation wheels: a - rigid wheelset; $\mathrm{b}$ - independent rotation wheels 
When the wheel axle stiffness is taken into account, the wheelset characteristic is between the rigid wheelset and the independent rotation wheels. The left and right wheels are elastically coupled together and the wheel axle torsion and bending stiffness will allow the wheel/rail contact geometry to have some variation compared with the rigid wheel axle. The left and right wheels will have a longitudinal phase difference due to the torsion stiffness, and the wheel/rail contact point and the direction of the normal force will change according to the bending stiffness which will increase the wheel/rail dynamic force to a certain extent. Fig. 2 shows a wheelset which takes into consideration the wheel axle elasticity and the influence of the wheel axle stiffness on the direction of the normal force, $k \_$axle is the wheel axle stiffness. The dotted line in Fig. $2 \mathrm{~b}$ represents the initial state of the wheelset and the solid line means the condition of the elastic wheelset when suffering a vertical load. It is clearly evident that the vertical deflection on the wheel axle is large when the stiffness especially the bending stiffness of the wheel axle is not sufficient, and the direction of the normal force of the two wheel/rail contact points will change greatly.

When the torsion stiffness of the wheel axle is large (small), the studied wheelset can be considered to be $a(n)$ rigid wheelset (independent rotation wheels). When the wheel axle stiffness is not sufficient, especially the bending stiffness perhaps due to faulty design, the vertical deflection of the wheel axle will become large and affect the wheel/rail contact force of the two wheels, increase the wheel/rail dynamic variable and the wheelset vibration, etc. This effect will also worsen the wheel/rail contact geometry condition, allow the wheel/rail abnormal wear phenomenon to happen, and seriously threaten the service life of the wheel axle.

\section{Dynamic Simulation Model}

The metro vehicle dynamic model is made up by 1 car body, 2 bogies, 4 wheelsets, 8 inner journal boxes, 8 outer journal boxes, 2 sets of anti-roll torsion bars, 2 Linear

a)

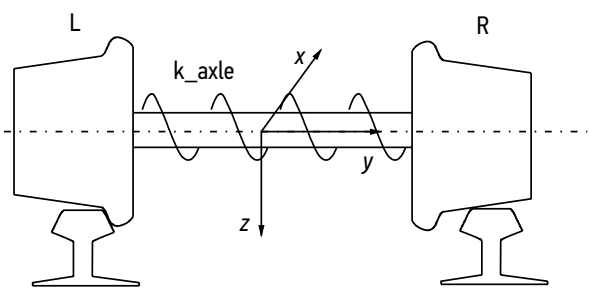

b)

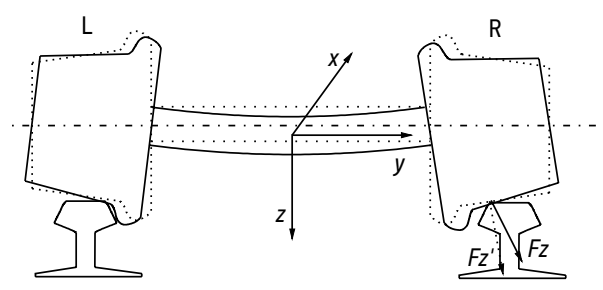

Fig. 2. The wheelset which considered the wheel axle stiffness function and the influence of the wheel axle stiffness function on the wheel/rail normal contact force: a - elastic wheel axle; $b$ - vertical deflection of the wheel axle
Induction Motors (LIM) and 14 LIM suspenders, and so on. All body components were considered to be rigid bodies except the wheelset.

The main components of the bogie are made up of a pair of wheelset, LIM, bogie frame, inner and outer journal box, bolster, anti-roll bar and a balance beam. The degrees of freedom of all the bodies are set up according to actual operation conditions. In addition, the main components and suspension parameters also fully consider the nonlinear characteristics of the primary suspension spring, air spring, dampers and the wheel/rail contact geometry. The radius of the wheelset was $0.365 \mathrm{~m}$, the LMA type wheel tread and $60 \mathrm{~kg} / \mathrm{m}$ weight rail were adopted, the cant of the rail was $1 / 40$ (Lao 2008). The model was set up by the dynamic simulation software SIMPACK, shown in Fig. 3, where the full load condition was taken as an example to carry out the studies; the detailed parameters of the model were shown in Table. Since there are no real measured track irregularities for the metro vehicle line of China, the commonly used German track irregularities were adopted for the model.

The rigid and elastic wheelset models were considered in the vehicle dynamic model. During the modelling of the elastic wheelset, the finite element model of the wheelset was first modelled in the software ANSYS, then the elastic wheelset file, containing the wheelset mode, stiffness characteristic and node degrees of freedom, was formed through the Guyan method, as is shown in Fig. 4a. The rigid-flexible coupling vehicle dynamic model was set up through the imported elastic wheelset model and the vehicle model (Schupp et al. 1999).

Both the wheel and the rail develop a minimal elastic deformation at the wheel/rail contact region, however this deformation can be omitted when taking considering the structure deformation of the wheelset and the rail (Arnold et al. 2004). Hence, the wheel/rail contact was considered to be a rigid contact relation in this paper, and no longer considered the minimal elastic deformation of the wheel/rail contact region, the influence of the rail deformation was not researched in this paper, and mainly analysing the influence of the wheel axle elasticity. The wheel/rail contact geometry of the LMA type tread and the $60 \mathrm{~kg} / \mathrm{m}$ rail are shown in Fig. $4 b$.

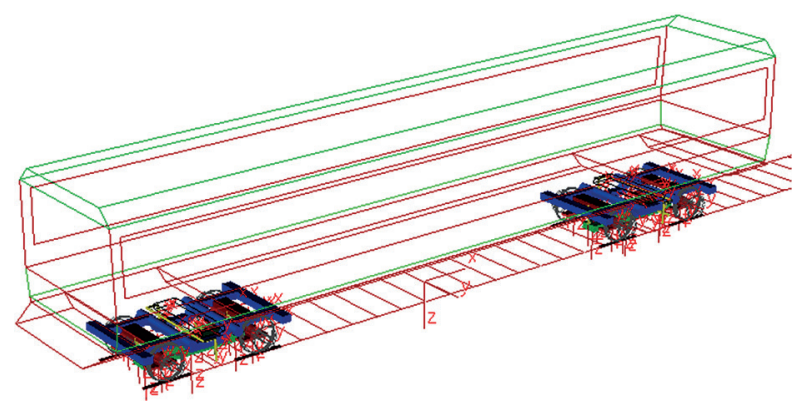

Fig. 3. The linear metro vehicle dynamic model 
Table. Main suspension parameters of the vehicle

\begin{tabular}{|c|c|c|c|}
\hline $\begin{array}{l}\text { Serial } \\
\text { number }\end{array}$ & Parameters & Value & Units \\
\hline 1 & Wheel base & 2000 & $\mathrm{~mm}$ \\
\hline 2 & Car body base & 12000 & $\mathrm{~mm}$ \\
\hline 3 & $\begin{array}{l}\text { The transverse } \\
\text { distance of the two } \\
\text { outer journal boxes }\end{array}$ & 2010 & $\mathrm{~mm}$ \\
\hline 4 & $\begin{array}{l}\text { The transverse } \\
\text { distance of the two } \\
\text { outer journal boxes }\end{array}$ & 920 & $\mathrm{~mm}$ \\
\hline 5 & Car body mass & 17529 & $\mathrm{~kg}$ \\
\hline 6 & $\begin{array}{l}\text { Body vertical centre } \\
\text { mass }\end{array}$ & 1400 & $\mathrm{~mm}$ \\
\hline 7 & Bogie mass & 1102 & $\mathrm{~kg}$ \\
\hline 8 & Balance beam & 63.6 & $\mathrm{~kg}$ \\
\hline 9 & $\begin{array}{l}\text { Traction motor } \\
\text { mass }\end{array}$ & 1480 & $\mathrm{~kg}$ \\
\hline 10 & Wheelset mass & 1007 & $\mathrm{~kg}$ \\
\hline 11 & Wheelset radius & 365 & $\mathrm{~mm}$ \\
\hline 12 & $\begin{array}{l}\text { Primary suspension } \\
\text { stiffness }(x / y / z)\end{array}$ & $\begin{array}{l}5200 / 5200 / \\
1200\end{array}$ & $\mathrm{kN} / \mathrm{m}$ \\
\hline 13 & $\begin{array}{l}\text { Primary damper } \\
z \text {-axis }\end{array}$ & 4 & $\mathrm{kN} \cdot \mathrm{s} / \mathrm{m}$ \\
\hline 14 & $\begin{array}{l}\text { Secondary } \\
\text { suspension stiffness } \\
(x / y / z)\end{array}$ & $130 / 130 / 40$ & $\mathrm{kN} / \mathrm{m}$ \\
\hline 15 & $\begin{array}{l}\text { Secondary damper } \\
(y / z)\end{array}$ & $40 / 35$ & $\mathrm{kN} \cdot \mathrm{s} / \mathrm{m}$ \\
\hline 16 & $\begin{array}{l}\text { Supporting stiffness } \\
\text { of the balance beam } \\
(x / y / z)\end{array}$ & $\begin{array}{c}15000 / 20000 / \\
30000\end{array}$ & $\mathrm{kN} / \mathrm{m}$ \\
\hline 17 & $\begin{array}{l}\text { Traction motor } \\
\text { vertical suspender } \\
\text { suspension stiffness } \\
(x / y / z)\end{array}$ & $\begin{array}{c}240000 / 200000 / \\
240000\end{array}$ & $\mathrm{kN} / \mathrm{m}$ \\
\hline 18 & $\begin{array}{l}\text { Traction motor } \\
\text { transverse suspender } \\
\text { suspension stiffness } \\
(x / y / z)\end{array}$ & $500 / 300 / 500$ & $\mathrm{kN} / \mathrm{m}$ \\
\hline 19 & $\begin{array}{l}\text { Traction bar } \\
\text { stiffness } x \text {-axis }\end{array}$ & 15000 & $\mathrm{kN} / \mathrm{m}$ \\
\hline
\end{tabular}

a)

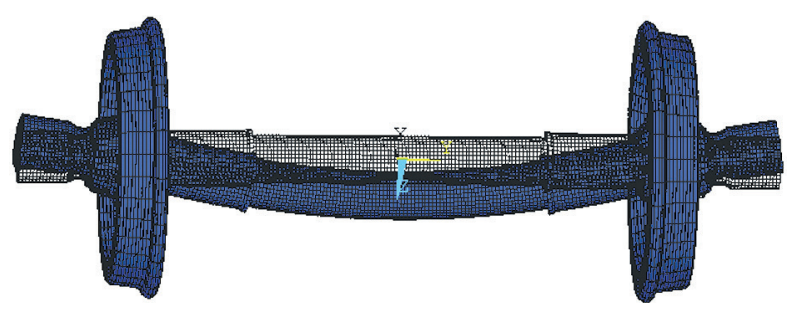

\section{Results Analyses}

This linear motor metro vehicle adopted the BM3000 type wheelset. Since this type of wheelset has a very serious wheel tread wearing problem, the wheel/rail dynamic contact force and wheelset vertical vibration were analyzed here. Based on the metro vehicle dynamic model, vehicle dynamics simulation analyses on the straight track were carried out to study the characteristics of the wheelset vertical vibration, wheel/rail vertical force and the influence of the wheel axle bending stiffness on wheelset vertical vibration and wheel/rail vertical force.

\subsection{Wheelset Vertical Vibration Acceleration}

Results of the wheelset vertical vibration acceleration of the metro vehicle on the straight track are shown in Fig. 5 for the two cases when the model adopted a rigid and elastic wheelset. The running speed was $75 \mathrm{~km} / \mathrm{h}$ for duration of $20 \mathrm{~s}$. The highest value of the wheelset vertical vibration acceleration was near $6 \mathrm{~m} / \mathrm{s}^{2}$ when the rigid wheelset model is adopted, while the same value was about $16 \mathrm{~m} / \mathrm{s}^{2}$ for the elastic wheelset model. The results of the elastic wheelset model differ markedly from the results of the rigid wheelset model leading to the conclusion that the smaller the wheel axle bending stiffness, the more the wheelset vertical vibration will increased. And which will worsen the wheel/rail contact environment and then increase the wheel/rail wear problem.

The vertical vibration acceleration of the two models was studied further in the running speed range between $40 \mathrm{~km} / \mathrm{h}$ to $100 \mathrm{~km} / \mathrm{h}$, displayed in Fig. 6. Results show that the maximal vertical vibration acceleration of the elastic wheelset was larger than the rigid wheelset in the entire studied range, the difference between the two models started to increase more starting at speeds above $70 \mathrm{~km} / \mathrm{h}$. Results show that during high speed operating conditions, a more serious wheelset vertical vibration acceleration will be experienced if the wheel axle bending stiffness is not large enough, and it also reflects that the wheel axle bending stiffness has a significant influence on the wheelset vertical vibration, especially at high speeds.

A vertical bending deformation occurs on the wheel axle when the wheelset suffers a vertical pressing force stemming from the bogie and the carbody. As a result,

b)

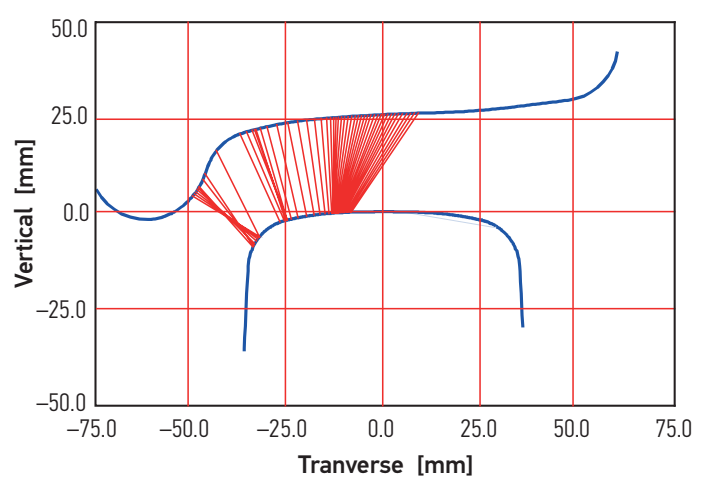

Fig. 4. The elastic wheelset model and the wheel/rail contact geometry: a - elastic wheelset model; $\mathrm{b}$ - wheel/rail contact geometry 
a)

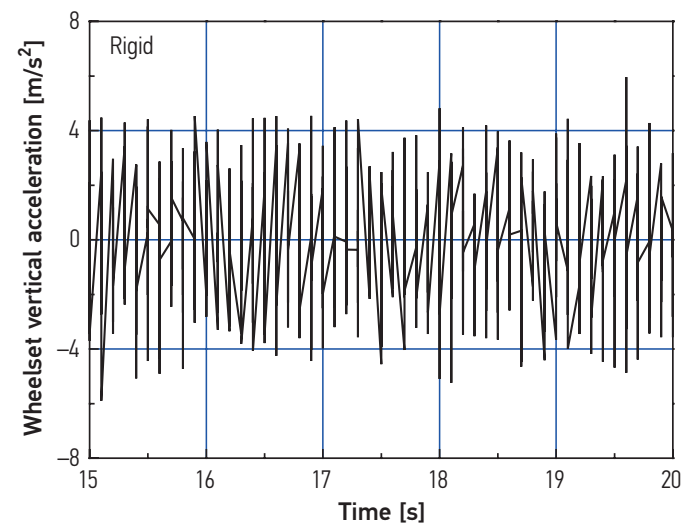

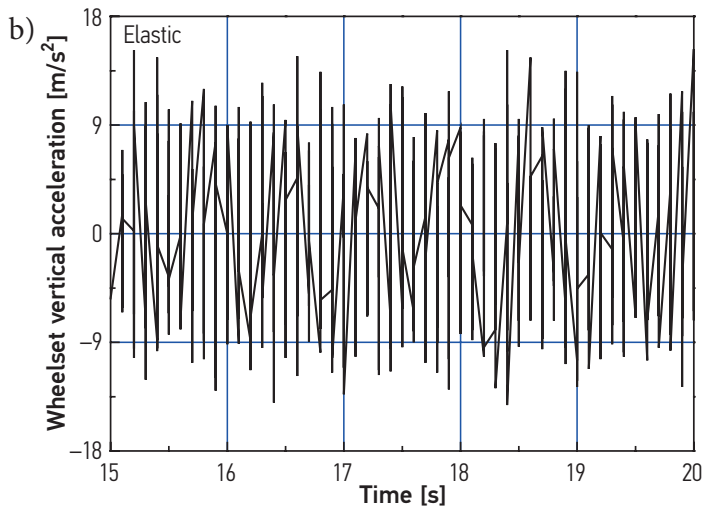

Fig. 5. Time history of wheelset vertical accelerations as a function of rigid and elastic model: a - rigid; b - elastic

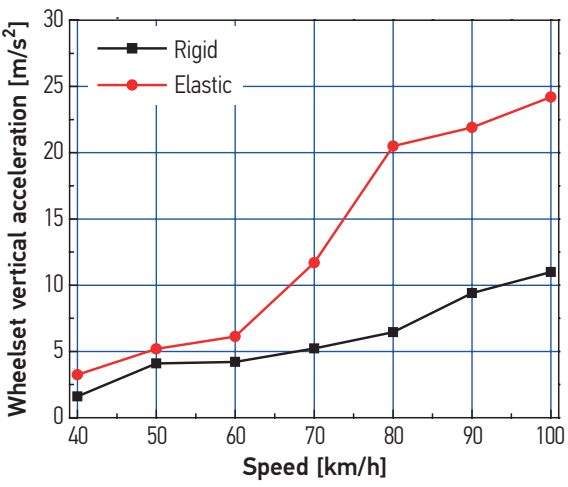

Fig. 6. The wheelset absolute maximum vertical vibration acceleration under different speeds

a vertical centrifugal acceleration of the wheel axle is caused by the deformation due to the continual rotation of the wheelset which ultimately leads to an increase of the vertical vibration acceleration of the wheelset. As the wheel axle elastic factor is ignored in the rigid wheelset model, the elastic wheelset model will better reflect the real operating conditions of the wheelset than the rigid model.

The frequencies of the wheelset vertical vibration acceleration under different speeds are shown in Fig. 7, from which it can be clearly seen that the main vibration frequency was similar under the studied speeds, especially at higher speeds. The wheelset vertical vibration with the frequency of $32 \mathrm{~Hz}$ was higher when the speeds were $75 \mathrm{~km} / \mathrm{h}$ and $100 \mathrm{~km} / \mathrm{h}$ than when it was $50 \mathrm{~km} / \mathrm{h}$, which shows how the maximal wheelset vertical vibration acceleration shifts with respect to an increase of the running speed. For the BM3000 type wheelset, the fixed vibration frequency is near $32 \mathrm{~Hz}$ which is determined by the structure and the mass of the wheelset and independent to the running speed.

\subsection{Wheel/Rail Vertical Dynamic Force}

The wheel/rail vertical dynamic force of the two models which adopted the BM3000 elastic wheelset and rigid wheelset at a running speed of $75 \mathrm{~km} / \mathrm{h}$ are displayed in Figs $8 \mathrm{a}$ and $8 \mathrm{~b}$, respectively. The calculations were performed on the straight track and the calculation time
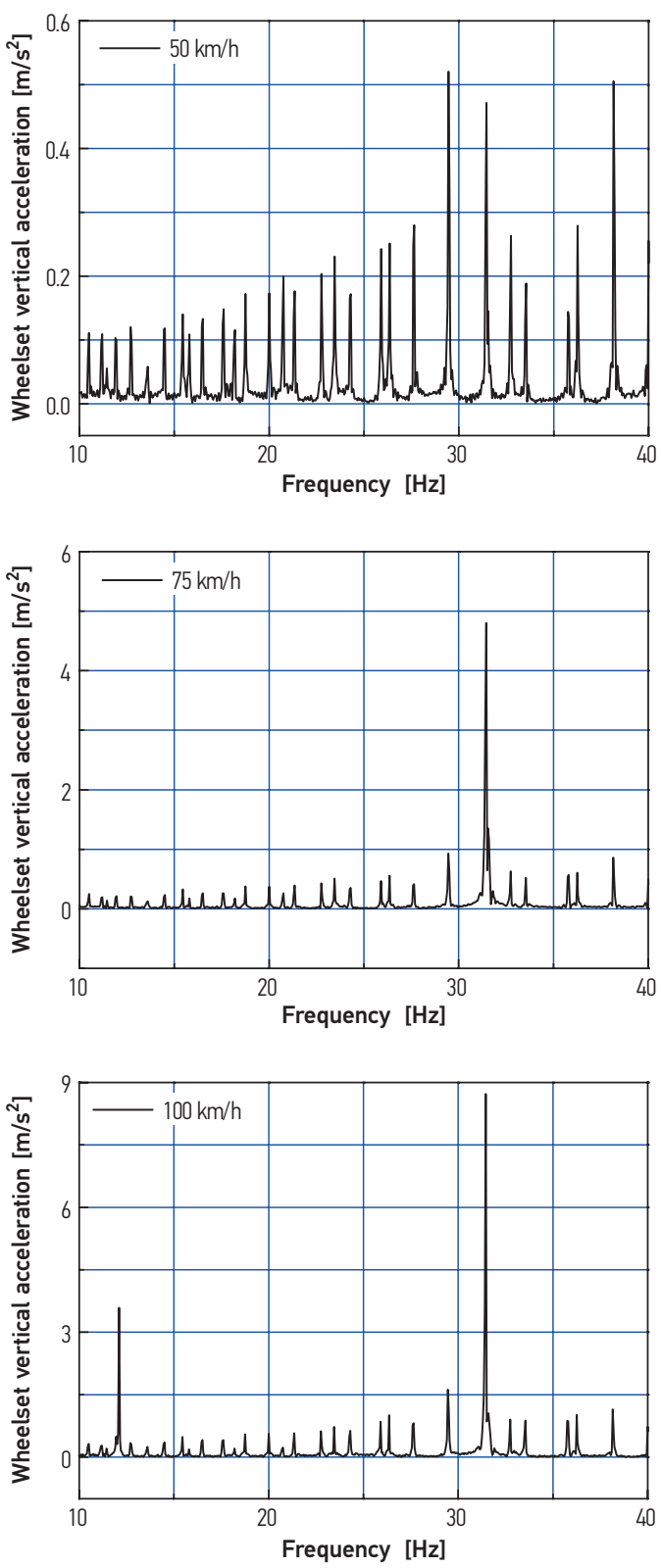

Fig. 7. The wheelset vertical vibration acceleration frequency content 
a)

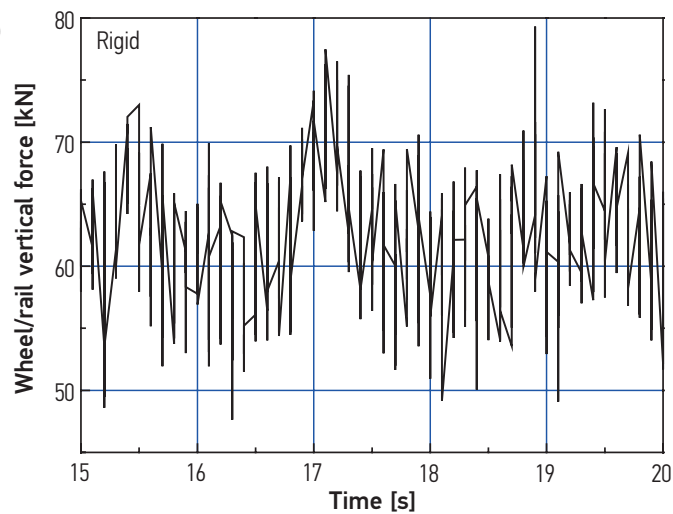

b)

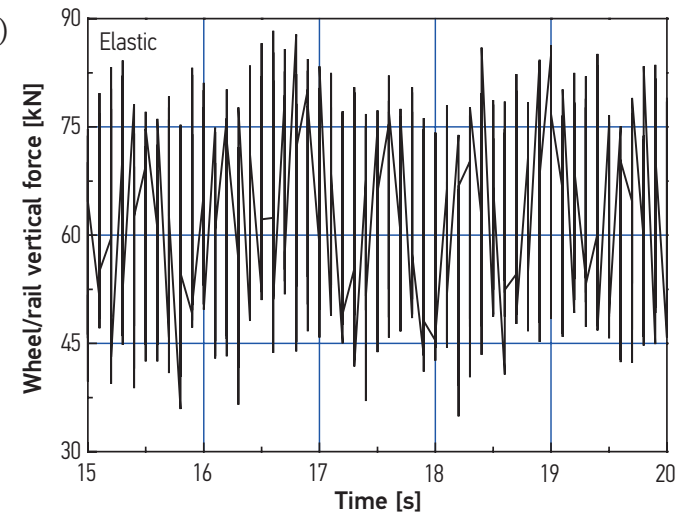

Fig. 8. Time history of wheel/rail vertical force as a function of rigid and elastic model: a - rigid; b - elastic

was $20 \mathrm{~s}$. Here, Fig. 8 only displays the time history of the wheel/rail vertical force from the $15 \mathrm{~s}$ to $20 \mathrm{~s}$ range.

As is observed in Fig. 8a, the largest value of the wheel/rail vertical force did not exceed $80 \mathrm{kN}$ for the metro vehicle which adopts the rigid wheelset model. For the elastic model, the largest value was close to $90 \mathrm{kN}$, however, more dynamic changes were observed relative to the rigid model. The difference between the large amounts of vibrations experienced by the two models can be attributed to the difference in elasticity of the wheel axle and the wheel axle bending stiffness. The elastic stiffness of the wheel axle will increase the wheel/rail vertical force compared with the rigid wheelset.

Fig. 9 depicts the results of the maximum wheel/rail vertical force of the two models when the BM3000 type elastic wheelset and rigid wheelset are adopted under different running speeds. The wheel/rail vertical force of the two studied models increases almost in a linear fashion with respect to an increase of the running speed. All throughout the studied range of the running speed, the vertical vibration of the rigid wheelset model was smaller than the elastic wheelset model by an average of $9 \mathrm{kN}$. For the rigid wheelset model, the wheel/rail vertical force of the metro vehicle was $93 \mathrm{kN}$ at the highest studied running speed of $100 \mathrm{~km} / \mathrm{h}$, while the corresponding value for the elastic wheelset model was $107 \mathrm{kN}$, a difference of nearly $15 \%$.

For the BM3000 type wheelset, when the elastic wheelset model was adopted, all the results of the wheel-

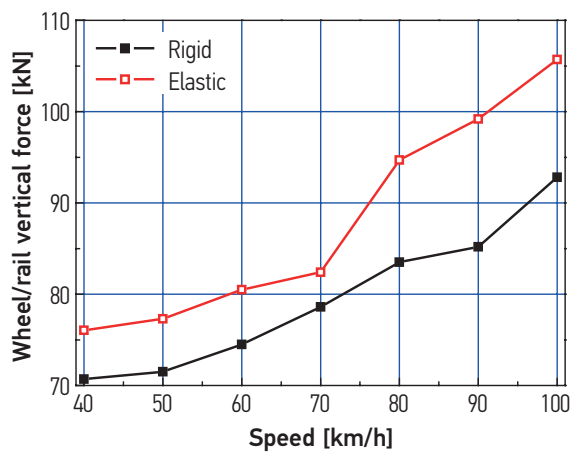

Fig. 9. The wheel/rail absolute maximum vertical force under different speeds set vertical vibration acceleration dynamic changed, the peak value and the dynamic changes of the wheel/rail vertical force underwent a large increase relative to the rigid wheelset model. This also means that the wheel axle bending stiffness of the BM3000 type wheelset is not big enough, and will increase the wheelset vertical vibration and wheel/rail vertical force during the running, which in the long run, will inevitably accelerate the wheel/rail wear phenomenon.

\subsection{Wheel Axle Vertical Dynamic Deflection}

For the BM3000 type wheelset, the minimal diameter of the wheel axle is $136 \mathrm{~mm}$, and the mass of the wheel axle is $260 \mathrm{~kg}$. From finite element analyses calculations on the BM3000 type wheelset, the vertical deformation of the wheel axle was $0.669 \cdot 10^{-4} \mathrm{~m}$ when the wheel axle was subject to a $10 \mathrm{kN}$ vertical force yielding an equivalent bending stiffness of about $1.43 \cdot 10^{8} \mathrm{~N} / \mathrm{m}$.

The wheel axle of the BM3000 type wheelset has a smaller dimension and lower mass relative to other wheelset models. As a result of these two factors, the vertical bending stiffness is not sufficiently large which may be the source of the observed large wheel/rail vertical forces and wheelset vertical vibration accelerations. As an example, the wheelset adopted by the Beijing Metro Vehicle (BJMV) is compared to the results obtained with the BM3000 type wheelset model. For the BJMV type wheelset, the minimal diameter of the wheel axle is $160 \mathrm{~mm}$, and the mass of the wheel axle is $305 \mathrm{~kg}$. The results from our finite element analyses on the BJMV type wheelset show that the vertical deformation of the wheel axle was $1.1476 \cdot 10^{-4} \mathrm{~m}$ when subject to $10 \mathrm{kN}$ of vertical force which yields an equivalent bending stiffness of $8.7 \cdot 10^{8} \mathrm{~N} / \mathrm{m}$. The bending stiffness of the BJMV type wheelset was about 6 times bigger than that of the BM3000 type wheelset.

Fig. 10 displays the wheel axle vertical deformation results of two models that adopted the BM3000 type elastic wheelset and BJMV type elastic wheelset at the running speed of $75 \mathrm{~km} / \mathrm{h}$. It can be seen clearly from Fig. 10 that the largest wheel axle vertical deformation of the BM3000 type wheelset is nearly $1.5 \mathrm{~mm}$ while the value of the BJMV is about $0.22 \mathrm{~mm}$. For the BJMV type elastic wheelset model, the wheel axle vertical deforma- 

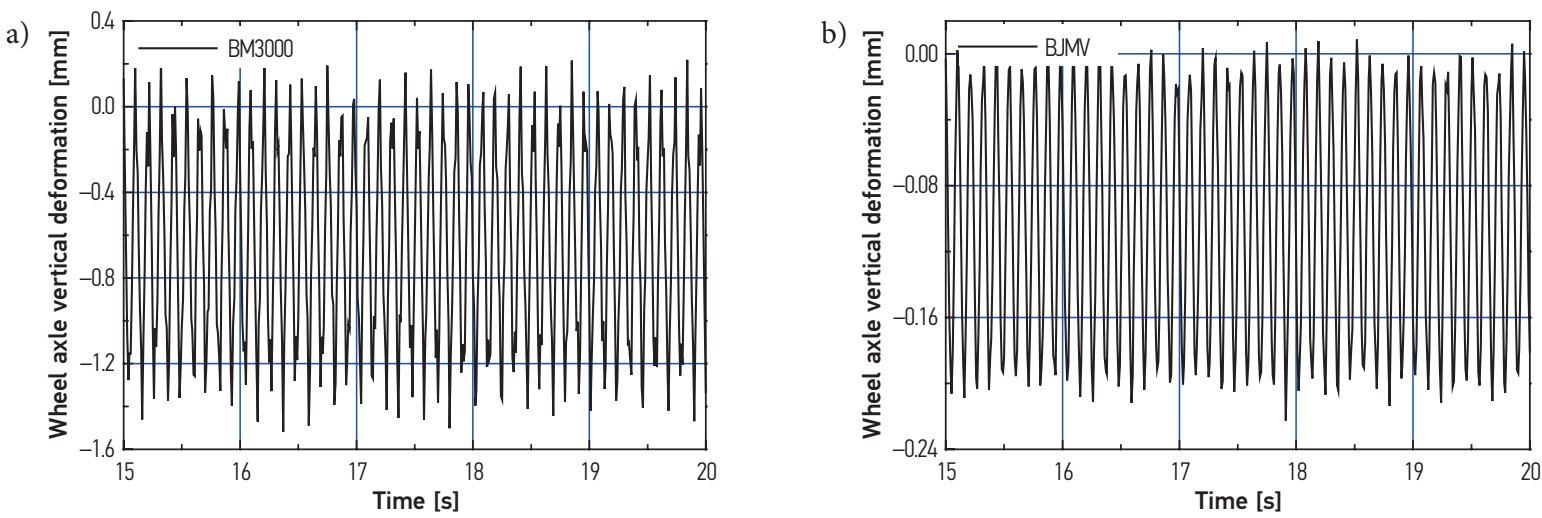

Fig. 10. Time history of wheel axle deformation changes of two kinds of wheelset models: a - BM3000; b - BJMV

tion changes were quite small as it had a bigger wheel axle diameter, so the results from this is closer to the results of the rigid wheelset model.

After decrease the wheelset vertical vibration acceleration and the wheel/rail vertical force, an improvement of the wheel/rail wear and damage problem can be obtained, a method to increase the wheel axle bending stiffness is put forward in this paper through the decrease of the wheel axle vertical deformation. The wheel axle bending stiffness can be increased through increments of the wheel axle diameter or improvement of the wheel axle material; this paper analyses the method of increasing the wheel axle diameter. The BJMV type wheelset which has a bigger wheel axle diameter than the BM3000 type wheelset is taken as the example to carry out the concerned issues.

\subsection{Influence of the Wheel Axle Bending Stiffness}

Timeframe snapshots of the wheelset vertical vibration acceleration and the wheel/rail vertical force of the model which adopts the BJMV type wheelset at the speed of $75 \mathrm{~km} / \mathrm{h}$ are shown in Fig. 11 and Fig. 12 for the elastic and rigid wheelsets, respectively.
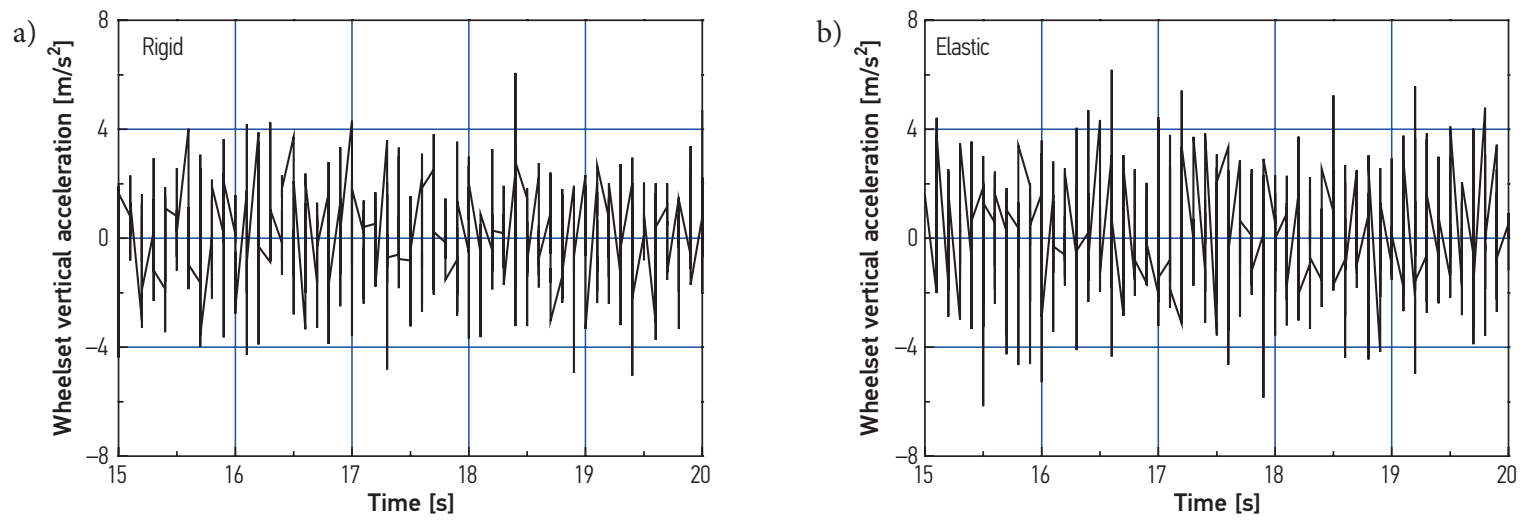

Fig. 11. Time history of wheelset vertical accelerations as a function of rigid and elastic model: a - rigid; b - elastic

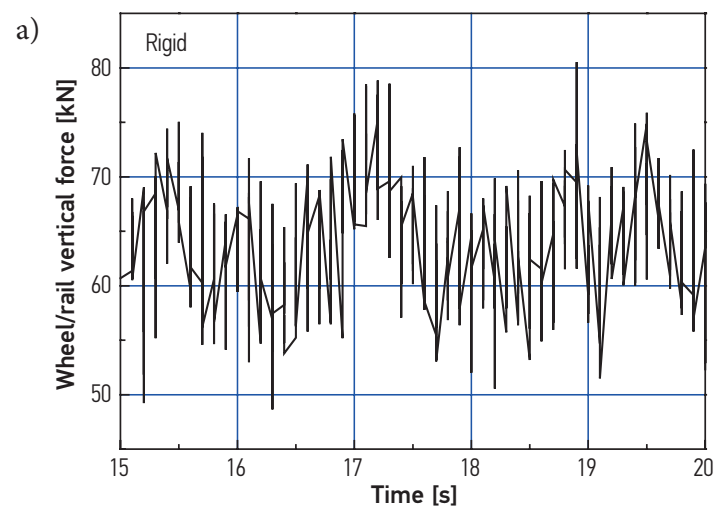

b)

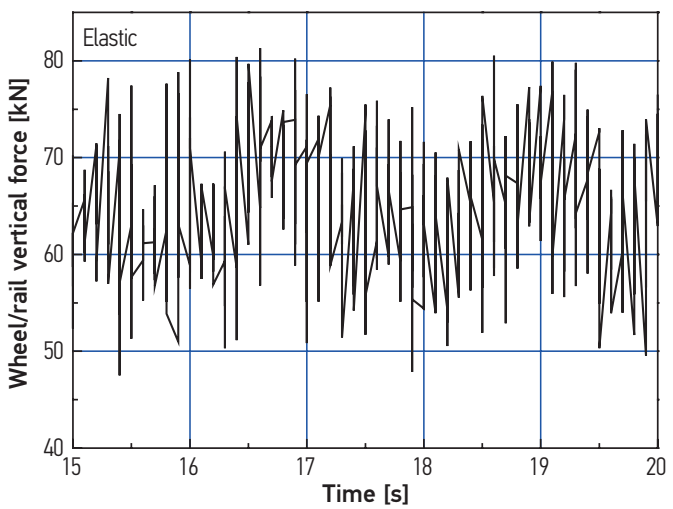

Fig. 12. Time history of wheel/rail vertical force as a function of rigid and elastic model: a - rigid; b - elastic 

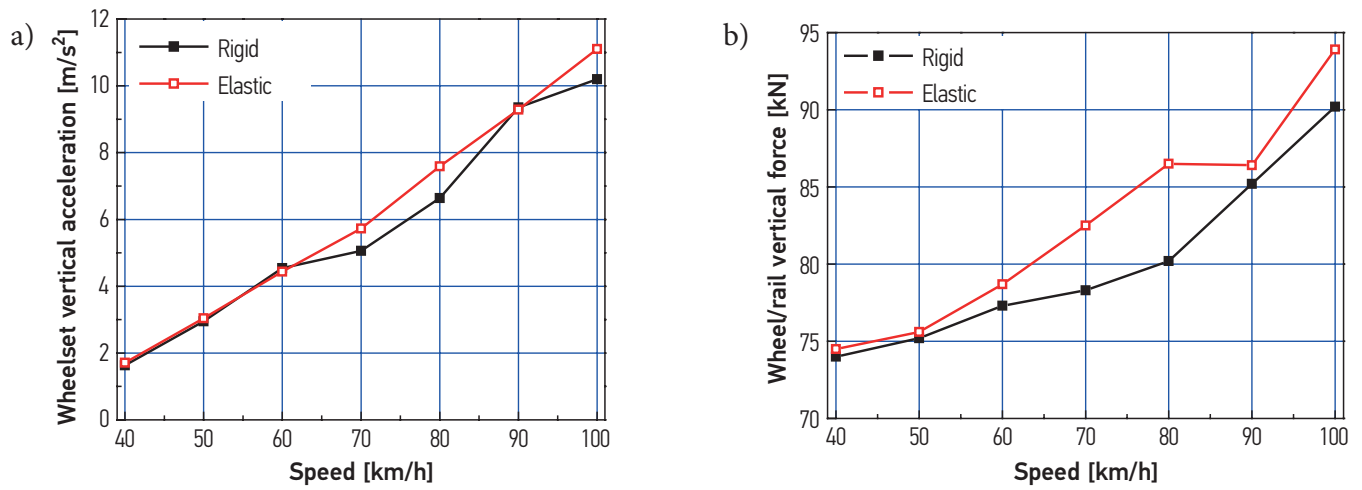

Fig. 13. The wheelset absolute maximum vertical vibration acceleration and the wheel/rail absolute maximum vertical force under different speeds: $\mathrm{a}$ - wheelset vertical acceleration; $\mathrm{b}$ - wheel/rail vertical force

From Fig. 12 it can be seen that the obtained results for the wheelset vertical vibration acceleration and the wheel/rail vertical force of the elastic wheelset model are similar to the results of the rigid wheelset model substantiating the fact that if the wheel axle bending stiffness is large enough, the wheelset vertical vibration acceleration and the wheel/rail vertical force will not be largely affected by the wheel axle bending stiffness. The results of the wheelset vertical vibration acceleration and the wheel/rail vertical force of the two models under different speeds are shown in Fig. 13.

Fig. 13a shows clearly how the wheelset vertical vibration acceleration of the elastic wheelset and the rigid wheelset for the BJMV type wheelset are close to one another when having a larger bending stiffness. At the same time, the wheel/rail vertical force of the elastic wheelset is also close to the results of the rigid wheelset, displayed in Fig. 13b. The wheel/rail vertical force is smaller than the BM3000 type wheelset when both adopt the elastic wheelset model. These results indicate that the larger wheel axle bending stiffness can decrease the wheelset vertical vibration acceleration, wheel/rail vertical force and effectively change the wheel axle vertical deformation. Therefore, the wheelset vertical vibration acceleration and the wheel/rail vertical force of the BJMV type wheelset can be reduced effectively when compared to the model that adopted the BM3000 type wheelset.

Fig. 14 presents the frequency of the wheelset vertical vibration acceleration of the rigid model of the

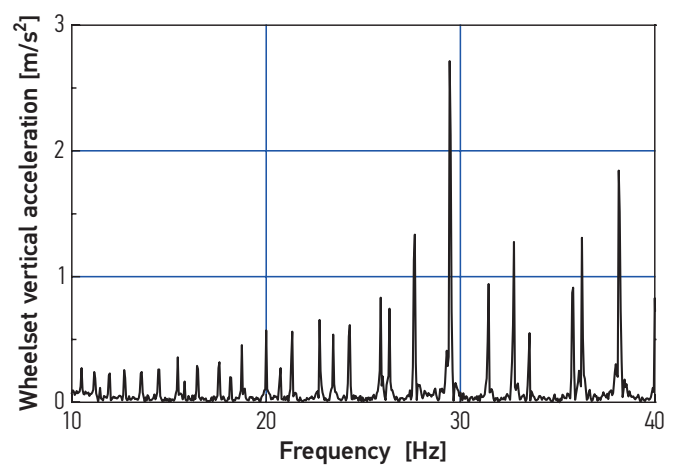

Fig. 14. The frequency of the wheelset vertical vibration acceleration
BJMV wheelset, the frequency of the wheelset vertical vibration can be observe to also undergo changes; the peak vibration at $32 \mathrm{~Hz}$ observed in the BM3000 type wheelset in Fig. 7 has disappeared. Both the peak value and the main vibration frequency of the BJMV type wheelset experienced a significant decrease, making the use of the employed method, via the increase of the wheel axle stiffness to reduce the wheelset vertical vibration acceleration and wheel/rail dynamic contact force, more feasible.

\section{Conclusions}

Through the comparison of dynamic simulations of the linear motor metro vehicle which adopted the BM3000 type and BJMV type wheelsets, some conclusions are drawn: 1. For the metro vehicle which adopted the BM3000 type elastic wheelset, the wheelset vertical vibration acceleration and wheel/rail vertical force increased rapidly with the increasing speed. A great difference was observed when compared to the model that adopted the rigid wheelset.

2. For the metro vehicle which adopted the BJMV type elastic wheelset, the results of the wheelset vertical vibration acceleration and the wheel/rail vertical force are very close to the results of the model which adopted the rigid wheelset, and the peak value of the wheelset vertical vibration and the main vibration frequency both experienced a significant decrease under unchanged parameters when compared to the model that adopted the BM3000 type wheelset.

3. The wheel axle bending stiffness had a significant influence on the wheel axle deflection, wheelset vertical vibration acceleration and the wheel/rail vertical force; a smaller wheel axle bending stiffness leads to a larger wheelset vertical acceleration and wheel/rail vertical dynamic force, which goes against the improvement of the wheel/rail contact environment.

Although in general, the wheelset vertical vibration acceleration and wheel/rail vertical force can be reduced effectively through the increase of the diameter of the wheel axle, a larger diameter does not automatically equate to a better performance. Other important factors must also be taken into consideration, such as the strength analyses and the axle load of the wheel axle. 


\section{Acknowledgements}

We thank the National Natural Science Foundation of China (Grant No. 51005190) for their aid and support, the New Century Excellent Talents program in University (Grant No. NCET-11-0712), the Science and Technology Project of Sichuan Province (Grant No. 2012GZ0103), the China Postdoctoral Science Foundation (Grant No. 2013M540715), the 'Sishi' Star program of Southwest Jiaotong University.

\section{References}

Arnold, J.; Kaiser, I.; Schupp, G. 2004. Simulation of a railway vehicle's running behaviour: how elastic wheelsets influence the simulation results, Vehicle System Dynamics 41 (Suppl.): 242-251.

Auciello, J.; Meli, E.; Falomi, S.; Malvezzi, M. 2009. Dynamic simulation of railway vehicles: wheel/rail contact analysis, Vehicle System Dynamics 47(7): 867-899. http://dx.doi.org/10.1080/00423110802464624

Baeza, L.; Fayos, J.; Roda, A.; Insa, R. 2008. High frequency railway vehicle-track dynamics through flexible rotating wheelsets, Vehicle System Dynamics 46(7): 647-659. http://dx.doi.org/10.1080/00423110701656148

Chaar, N.; Berg, M. 2006. Simulation of vehicle-track interaction with flexible wheelsets, moving track models and field tests, Vehicle System Dynamics 44(Suppl. 1): 921-931. http://dx.doi.org/10.1080/00423110600907667

Chaar, N.; Berg, M. 2005. Vehicle-track dynamic simulations of a locomotive considering wheelset structural flexibility and comparison with measurements, Proceedings of the Institution of Mechanical Engineers, Part F: Journal of Rail and Rapid Transit 219(4): 225-238.

http://dx.doi.org/10.1243/095440905X8907

Iwnicki, S. 2009. Future trends in railway engineering, Proceedings of the Institution of Mechanical Engineers, Part C: Journal of Mechanical Engineering Science 223(12): 2743-2750. http://dx.doi.org/10.1243/09544062JMES1545

Iwnicki, S. 2003. Simulation of wheel-rail contact forces, Fatigue \& Fracture of Engineering Materials \& Structures 26(10): 887-900.

http://dx.doi.org/10.1046/j.1460-2695.2003.00699.x

Jin, X.; Wu, P.; Wen, Z. 2002. Effects of structure elastic deformations of wheelset and track on creep forces of wheel/rail in rolling contact, Wear 253(1-2): 247-256. http://dx.doi.org/10.1016/S0043-1648(02)00108-4

Kaiser, I.; Popp, K. 2006. Interaction of elastic wheelsets and elastic rails: modelling and simulation, Vehicle System Dynamics 44 (Suppl. 1): 932-939.

http://dx.doi.org/10.1080/00423110600907675

Knothe, K.; Grassie, S. L. 1993. Modelling of railway track and vehicle/track interaction at high frequencies, Vehicle System Dynamics 22(3-4): 209-262. http://dx.doi.org/10.1080/00423119308969027

Kouroussis, G.; Verlinden, O.; Conti, C. 2010. On the interest of integrating vehicle dynamics for the ground propagation of vibrations: the case of urban railway traffic, Vehicle System Dynamics 48(12): 1553-1571.

http://dx.doi.org/10.1080/00423111003602392

Lao, J.-J. 2008. Flexible bogie of linear motor vehicle on Guangzhou metro line 4, Electric Locomotives \& Mass Transit Vehicles 31: 44-46.
Li, X.; Wen, Z. F.; Jin, X. S. 2010. Analysis of abnormal wear on metro wheel tread, Journal of Mechanical Engineering 46(16): 60-66. http://dx.doi.org/10.3901/JME.2010.16.060

Ma, W. H.; Luo, S. H.; Song, R. R. 2011. Analysis of wheel set longitudinal vibration and the correlated dynamic performance, Applied Mechanics and Materials 52-54(1): 1-6. http://dx.doi.org/10.4028/www.scientific.net/AMM.52-54.1

Ma, W. H.; Luo, S. H.; Song, R. R. 2006. Influence of track irregularity on longitudinal vibration of wheelset and correlation performance, Journal of Southwest Jiaotong University (English Edition) 14(3): 238-251.

Madia, M.; Beretta, S.; Zerbst, U. 2008. An investigation on the influence of rotary bending and press fitting on stress intensity factors and fatigue crack growth in railway axles, Engineering Fracture Mechanics 75(8): 1906-1920. http://dx.doi.org/10.1016/j.engfracmech.2007.08.015

Meywerk, M. 1999. Polygonalization of railway wheels, Archive of Applied Mechanics 69(2): 105-120. http://dx.doi.org/10.1007/s004190050208

Schupp, G.; Netter, H.; Mauer, L.; Gretzschel, M. 1999. Multibody system simulation of railway vehicles with SIMPACK, Vehicle System Dynamics 31(Suppl.): 101-118.

Wang, P.; Liu, X. Y.; Wan, F. G. 1996. Torsional vibration of wheelsets and curved rail corrugations, Journal of Southwest Jiaotong University 31: 58-62.

Wickens, A. H. 2003. Fundamentals of Rail Vehicle Dynamics: Guidance and Stability. Taylor \& Francis. 295 p.

Xu, H.; Yuan, H.; Wang, L.; Na, W. B.; Xu, W. B.; Li, Y. T. 2010. Modeling of metro wheel wear and optimization of the wheel re-profiling strategy based on Gaussian processes, Journal of Mechanical Engineering 46(24): 88-95. http://dx.doi.org/10.3901/JME.2010.24.088

Zerbst, U.; Mädler, K.; Hintze, H. 2005. Fracture mechanics in railway applications - an overview, Engineering Fracture Mechanics 72(2): 163-194. http://dx.doi.org/10.1016/j.engfracmech.2003.11.010

Zhang, Y. G. 2009. A study of the wheel axle vibration performance of the trail vehicle of the CRH2-300 type EMU. Beijing Jiaotong University, Beijing (in Chinese).

Zhao, Y. X.; Gao, Q.; Zhang, B.; Diao, K. J. 2010. Key solid mechanics issues and research progresses for railway vehicle wheelset, Chinese Journal of Solid Mechanics 31: 716-730. 